\title{
Corrigendum
}

\section{State Sales Tax Rates for Soft Drinks and Snacks Sold through Grocery Stores and Vending Machines, 2007}

Jamie F. Chriqui, Shelby Smith Eidson, Hannalori Bates, Shelly Kowalczyk and Frank J. Chaloupka

Journal of Public Health Policy (2009) 30, 364. doi:I0.I057/jphp.2009.29

Correction to: Journal of Public Health Policy (2008) 29, $226-249$. doi:IO.I057/jphp.2008.9

The discussion of the applicability of state non-sales taxes (for example, excise taxes) to Food Stamp purchases on page 244 of the referenced article was incorrect. In fact, all purchases made with Food Stamps are exempt from any state taxes - sales, excise or other taxes. The authors apologize for this error. It should be noted, however, that any purchases made outside of the Food Stamp allotment would be subject to any and all applicable state taxes including both sales and excise taxes. 